French presidential election Good for science?

Champagne corks were popping in science departments throughout France on Monday at the news that François Mitterand, socialist party leader, was to be France's next President. Not that most French scientists are socialists; rather, that science will take a leap forward in France if Mitterand sticks to his announced policies.

Mitterand has promised a "national council for science and culture", reporting to the president, and has announced that spending on research and development in France should reach 2.5 per cent of gross national product by 1985 , compared with the present 1.8 per cent. Mitterand's goal could only be reached with high government spending, for French industry is notably niggardly in its provision for science; Giscard had a more cautious target of 2.3 per cent by 1988 .

The socialist leader has also said he will raise the rank of the minister of science to full cabinet level, so the minister will participate in all major policy decisions. (The current incumbent, Pierre Aigrain, attends cabinet only when matters involving science are under discussion.) Two names are being tipped for the job; François Gros, a biochemist at the Institut Pasteur, who has been active among scientists on Mitterand's behalf; and the career politician Jean-Pierre Chevenement, a member of the chamber of deputies who has taken an interest in scientific affairs. The high level of the post may favour the politician.

Mitterand will also set up a parliamentary special committee for technology assessment, something previously unheard of in France, where technological decisions have been reached in an entirely autocratic manner. The new president is also cool on nuclear power, so France's nuclear lead might be expected to slip unless national pride erodes the president's doubts. He has said he will call for a "pause" in nuclear construction after the reactors now under order, and the fast breeder Super-Phénix, are completed, in order to review the programme.

Robert Walgate

\section{French oceanography}

\section{Pulling together}

The outgoing French government completed the last leg of its reorganization of oceanographic research last month with the creation of a joint interdisciplinary programme between CNRS, which is the main funding body for scientific research, and the Ministry of Universities. The new programme is expected to be in full operation early next year. The reorganization, which began at the end of 1979 when an informal Comité d'Océanologie was set up to advise government, reflects the political importance in
France of technologies for exploiting the mineral and biological wealth of the oceans.

This attempt to coordinate research supportd by CNRS and the Ministry of Universities through the new Programme Interdisciplinaire de Recherche Océanographique (PIRO) is unusual in French research administration, for with the growth of support for oceanography since the Second World War, two disparate research programmes have grown up within the universities and the CNRS laboratories. Although similar difficulties have arisen in other fields, oceanographic research has been particularly affected, according to the director of PIRO, Roger Chesselet.

PIRO's task of coordination will fall to an eighteen-member scientific committee with an annual budget of 11 million FFr, the Ministry of Universities and CNRS each contributing half. The budget, which will be in addition to the 185 million $\mathrm{FFr}$ already spent on oceanographic research,

\section{Bazan protests}

The academic research community in Argentina has been disconcerted by the precipitate sacking of Professor Nicolas Bazan from his posts as Director of the Institute of Biochemical Research at Bahia Blanca and as Professor of Biological Chemistry at the University of the South. Professor Bazan (38) heard of his dismissal only when he returned to Argentina from the United States early in March, but it is held to have taken effect from the end of 1980 .

The most puzzling aspect of this development is that Professor Bazan has insisted that he has no connections with political organizations deemed subversive by the military regime. One explanation is that his success has made him the target for influential jealousy, another that his dismissal is intended as a reminder that the influence of the military persists in the universities of Argentina.

Dr Bazan is a neurochemist who has, in the past few months, been able to demonstrate that in rat models of epilepsy, arachidonic acid and other precursors of prostaglandins are released into the brain in large amounts. Professor Bazan had been planning an investigation of the presence of arachidonic acid in the cerebrospinal fluid of human patients suffering from epilepsy, on the assumption that the underlying cause is a membrane deficiency.

Since his dismissal, Professor Bazan has insisted that he will fight for reinstatement. He has been supported by the staff of his institute, which sent a letter of protest to the President of Argentina on 21 March. The Argentinian press has also covered Bazan's dismissal sympathetically. will be used to run and buy equipment for six small research vessels, and to foster collaboration between several research groups working on different aspects of the same problem. PIRO, whose members are CNRS administrators and oceanographers nominated by CNRS and the Ministry of Universities, will be keen to support fundamental research in physical and biological oceanography, leaving mineral exploration and the application of new technologies to the well-established Centre National pour l'Exploitation des Océans (CNEXO). A small amount of the extra 11 million FFr will, however, be spent on research equipment for use by CNRS and university staff on board CNEXO's large, ocean-going research vessels.

The setting up of PIRO follows the definition of three categories of research: research with short-term application supported by the departments of industry, transport and environment; research with medium- and long-term application supported by CNEXO; and fundamental research, the responsibility of the Ministry of Universities.

Under the new arrangements, the different organizations supporting oceanography will report to the Comité d'Oceánologie. France is also hoping to collaborate internationally, especially with developing countries, on pollution problems and the exploitation of ocean resources when the Law of the Sea becomes operational.

Judy Redfearn

\section{UK university finance}

\section{Truth looms}

British universities should know more clearly next week what the future holds. For then the University Grants Committee will put out a circular spelling out the basis on which recurrent grants will be distributed to individual universities in the next few years. This first circular will be followed in June by more detailed information about the proposed division of the recurrent grant for 1981-82 among individual universities.

The committee has been forced to this two-stage approach by the need for detailed consultation with the Department of Education and Science about ways of sweetening what must certainly be a bitter pill. Originally it had been intended that final allocations would be announced this month. One of the concessions wrung from the government is likely to be an assurance that recurrent funds for the universities will be held for the next three years at the levels suggested in the white paper on public expenditure published in March.

British universities may thus know where they stand more clearly than in recent years, when government support has been determined one year at a time. The promised grants will, in the government's opinion, nevertheless require many universities "to review the range and 
nature of their contribution."

Next week's letter from the grants committee is expected not to go so far as to suggest that some universities should close. The emphasis, instead, will be on financial economies within existing institutions, with the recommendation that universities should think of closing departments which, for one reason or another, do not meet tests of efficiency and effectiveness. Universities and those who work in them will be especially interested in whatever arrangements the committee suggests for dispensing with unwanted members of teaching staffs.

Dr Edward Parkes, chairman of the University Grants Committee, has, however, made it clear in his evidence to a parliamentary committee that the impending cuts will not be made uniformly across the board. Universities will also be affected differently by the still uncertain enrolment of overseas students for the coming academic year. In its Statistical Bulletin for April, the Department of Education and Science shows that overseas student numbers declined by 7 per cent between 1979-80 and 1980-81.

Enrolments between the same two years declined by 10 per cent. Although the universities as a whole have more successfully maintained overseas student numbers than other institutions of higher education, some among them are in serious trouble, while all fear that new enrolments next October will decline further.

One part of the government's package of support for the universities has, however, been decided. The equipment grant for British universities will be increased by about 11 per cent to $£ 76.7$ million for the academic year 1981-82.

\section{Hungarian research

Cost of elitism

\section{Budapest}

Budapest's Eotvos Lorand University is to have a new science building - at a time when the Hungarian government is drastically reducing spending in virtually every sector of the economy.

This is not the first time that the university has been promised such a building, which would unite its 44 small science "chairs" under one roof into four large departments - mathematics and physics, chemistry, life sciences and Earth sciences. Yet, in spite of the economic climate, the academics concerned are confident that this time the plans will come to fruition, because the reorganization can be justified as cost-effective. With all laboratories in close proximity, it will be possible for the various departments to share expensive equipment.

More significant in precipitating the decision, however, was the public debate on the role of the university, begun in May 1979 by the journal Magyar Tudomany, in which the reorganization of universities into large departments was favoured.

One of the government's aims is to break the tradition of academic elitism. Young scientists are reluctant to leave cosy academic niches in research institutes to enter the harsher world of industry and the universities. Although the reorganization will be welcome, any real moves to strengthen the role of the universities in research would first have to deal with one of the major grievances of Hungarian scientists, the difficulty of purchasing equipment and reagents from abroad.

Because of the centralization of foreign trade, such purchases have to go through a single import-export company, which means a delay of at least six months for every order. Hard currency is not the only problem - the same delay occurs with purchases from the Comecon bloc. Only in research projects with a government priority rating - such as work on genetic engineering done under contract with the chemical industry - can the purchasing process be accelerated.

Whenever this subject is raised with officialdom, scientists say, the response is always sympathetic - but without visible result. Until the matter is resolved, however, young scientists will have one more reason for seeking a long-term post in one of the Academy of Science's numerous research institutes. For the academy has its own purchasing agency, "Akadimport", and although the delays involved are still of the order of two months, this still gives such researchers a considerable edge.

Vera Rich

\section{Satellite-linked computers

Network planned

Several different groups in Britain are cooperating in an experiment to link computers via satellite. The idea is to demonstrate to home and overseas customers how British technology can help industry and research institutions with their communications problems. Project Universe, as the experiment is called, is being supported to the tune of $£ 3$ million for three years by the Department of Industry, the Science and Engineering Research Council, British Telecom and two private companies, GEC-Marconi and the software house Logica.

The experiment is mainly to demonstrate how groups of users such as universities and companies with offices in different centres can communicate with each other through networks of computers linked by land and satellite. Six laboratories will house rings of computers, based on a network designed at the University of Cambridge, and will be equipped with an earth-station consisting of a 3-m diameter dish a $14-\mathrm{GHz}$ radio transmitter and an $11-\mathrm{GHz}$ receiver. Communications within a laboratory will be via the land system and between laboratories via one channel of the European Space Agency's Orbital Test
Satellite. Each computer will be able to communicate with any other in the system initially at a rate of 1 Megabit per second.

The Department of Industry, which is providing the largest sum of money, hopes that the project will help develop technology and demonstrate uses for the network.

The two major demonstrations of the network will be in transmitting large volumes of scientific and industrial data between centres. The Rutherford Laboratory is particularly keen to use the network to transmit mask design for largescale integrated circuits, developed with its electron beam lithography machine, to universities and industry.

The project is expected to be in operation early next year. It will run for two years throughout the rest of the life of the Orbital Test Satellite.

Judy Redfearn

\section{Research management}

\section{Audits go on}

Despite the tangle of legal threats, and claim and counter-claim over their previous - and still unpublished - work on Sir Bernard Lovell's radioastronomy at Jodrell Bank, a group of the Science Policy Research Unit (SPRU) at the University of Sussex has been given the go-ahead for its next study: CERN at Geneva.

The group is headed by Keith Pavitt, acting deputy director of SPRU, with principal researchers John Irvine and Ben Martin, who have developed what they call the method of "converging partial indicators" to assess the relative merits of scientific research groups.

Inevitably, this is dangerous territory, normally confined to the secrecy of peer review panels and referees' reports, and the Sussex group's serious attempt to arrive at objective criteria raised hackles as soon as it was applied to real cases, which included a comparison of radioastronomy groups in Britain and abroad and a study of British optical astronomy.

All these studies are now essentially complete, but none has been officially published - largely due to the Sussex group's procedure of checking its figures with the relevant laboratories first. Predictably, laboratories whose work is implicitly criticized object to either the figures or the conclusions.

The SPRU group, however, has been unable to consider such questions because at an early stage it was denied access to research council files under the "40 year rule", which controls the availability of government documents - even though the research councils are not government departments. It therefore could not assess the conditions under which one group, say, received a major grant, while another did not.

Nevertheless, what counts in the end is results, and the SPRU group claims to have a method which gives an objective assess- 